\section{DIOSA FORTUNA E IDENTIDADES BARROCAS}

\author{
José M. González García \\ Instituto de Filosofía - CCHS, CSIC \\ c/ Albasanz, 26 y 28 \\ 28037 Madrid \\ jmgonzalez1950@gmail.com
}

\section{THE GODDESS OF FORTUNE AND BAROQUE IDENTITIES}

\begin{abstract}
The title of this article refers to the two books I have worked in the University of Cambridge under the supervision of Peter Burke. The first book, The Goddess Fortune, was published in 2006 and won the Spanish National Prize for Non-fictional Literature in 2007. Now I am writing the second book, whose title will be Baroque Identities. This new concept is an "ideal-type" and refers critically to the two ways of constructing collective identities in contemporary political philosophy: kantian cosmopolitanism and political romanticism. The article's core is dedicated to the analysis of two key metaphors of baroque identities: the self as a labyrinth and the identity as a dream.
\end{abstract}

KEY WORDS: Goddess Fortune; identity; Baroque; labyrinth; dream.

Como el título de este artículo puede parecer incongruente a primera vista, quiero comenzar con una palabra de explicación: el título unifica en una sola frase los dos libros sobre los que he trabajado en la Universidad de Cambridge bajo la dirección de Peter Burke'. El primer libro, La diosa Fortuna. Metamorfosis de una metáfora política, se publicó a finales de 2006 y obtuvo en 2007 el Premio Nacional de Ensayo otorgado por el Ministerio de Cultura. El segundo libro, Identidades barrocas, empecé a escribirlo en la segunda mitad de 2007 y todavía me llevará algún tiempo terminarlo. Entre ambos libros hay, además, otro elemento común basado en la preocupación por el Barroco. Una parte importante de La diosa Fortuna está referida a la filosofía política, la literatura y la iconografía del siglo XVII. E Identidades barrocas parte del intento de clarificar las características que determinan al sujeto de esa misma época, sus formas de expresión y también de simulación/disimulación en el contexto de las cortes absolutistas europeas.

En el libro sobre la Fortuna se trata de un análisis de esta diosa desde el punto de vista de la historia cultural de las metáforas, alegorias e imágenes que impregnaron el
RESUMEN: El título de este artículo se refiere a los dos libros que he trabajado en la Universidad de Cambridge, bajo la dirección de Peter Burke. El primero, La diosa Fortuna, se publicó en 2006 y obtuvo el Premio Nacional de Ensayo en 2007. En la actualidad estoy escribiendo el segundo libro que llevará por título Identidades barrocas. Este nuevo concepto es un "tipo ideal" y se contrapone a las dos formas de construcción de identidades colectivas analizadas por la filosofía política contemporánea: el cosmopolitismo de cuño kantiano y el romanticismo político. El núcleo del artículo se dedica al análisis de dos de las metáforas fundamentales en que se expresa la identidad barroca en la literatura y en las artes: el yo como laberinto y la identidad como sueño.

PALABRAS CLAVE: Diosa Fortuna; identidad; Barroco; laberinto; sueño.

pensamiento político, la literatura y las artes durante el Renacimiento y el Barroco europeos. De manera multidisciplinar, analizo el tema de la Fortuna en tres claves fundamentales: iconografía, literatura y filosofía política. En la tradición iconográfica resultan especialmente importantes los temas de la Fortuna como diosa del Tiempo, sus relaciones con la Ocasión y también con la Vanidad del Mundo, la Melancolía y la Muerte. Además no debemos olvidar que la Fortuna es hija del Océano y responsable en determinadas épocas del cambio de vientos en el mar que originan las tormentas y el hundimiento de los barcos. Por ello fue venerada la Fortuna marina de forma especial por los marineros, pescadores y mercaderes. Estos últimos dependian de la razón técnica y económica representada por Mercurio, pero también de que la Fortuna hiciera llegar a puerto a las naves mercantes. En las tradiciones literarias europeas, el tema de la Fortuna está presente como un hilo rojo que recorre la Edad Media, el Renacimiento y el Barroco. Se invoca la protección de la Fortuna en todas las épocas de crisis colectiva, de guerra, azar e inseguridad, de transformación global de las relaciones sociales, épocas en las que los individuos se comprenden a sí mismos como dominados por fuerzas que no pueden controlar, 
que no comprenden y por ello atribuyen tanto poder a la figura personalizada de la diosa Fortuna que mueve a su capricho y volubilidad la rueda del cambio. Después de un recorrido por la literatura española, privilegio la barroca perspectiva de Gracián, pues en sus conceptos, metáforas y construcciones alegóricas sobre la Fortuna se dan la mano la tradición con todas sus figuras y la capacidad de invención de otras nuevas. En cuanto a la filosofía política me centro en dos momentos: en el siglo XVI analizo las reflexiones de Maquiavelo sobre el poder de la Fortuna en los asuntos humanos y cómo el Príncipe ha de enfrentarse a ella y dominarla, pues en la contraposición entre virtù y Fortuna se puede ver el núcleo central de su pensamiento. En el siglo XVII, estudio las empresas políticas de Saavedra Fajardo en que la Fortuna es utilizada como medio retórico para la educación del príncipe cristiano. En Saavedra se dan la mano el Barroco de la palabra con el Barroco de la imagen en esa conjunción de grabado y explicación textual en que consiste cada una de sus empresas.

Durante los siglos XVIII y XIX la diosa Fortuna pasa a un segundo plano, oscurecida por las luces de la razón y del progreso, pero no desaparece del todo. $Y$ regresa de nuevo en el siglo XX transmutada en otras categorías como las de azar, suerte, riesgo o destino. La segunda parte del libro se dedica al análisis de cuatro formas de recuperación de la diosa Fortuna, ya secularizada, en nuestra época: la fragilidad de la vida humana ante la tragedia y el amor, ya que éste no depende sólo de factores racionales sino también de la "buena suerte", como afirmara Max Weber; la compleja relación entre Fortuna y Justicia en algunos filósofos contemporáneos como John Rawls o Jon Elster; el retorno de la diosa Fortuna en la llamada "sociedad del riesgo"; y el poder de la Fortuna en los campos de concentración y de exterminio, pues los relatos de los supervivientes siempre han hecho hincapié en la necesidad de la suerte para sobrevivir, y de hecho, Primo Levi, consecuente con la tradición italiana, habla de intervenciones de la Fortuna necesarias para seguir con vida en tan extremas circunstancias. Así pues, en las esferas del Amor, la Justicia, el Riesgo y la Muerte hace su aparición la Fortuna contemporánea.

Pero como este libro sobre la diosa Fortuna ya ha sido publicado no quiero volver más aquí sobre él. El resto de este artículo estará dedicado a algunos elementos del segundo libro, también deudor de Peter Burke, en cuya escritura me encuentro trabajando actualmente y que llevará por título Identidades barrocas. Con este rótulo me quiero referir a una nueva categoria del análisis político de las identidades colectivas. En la filosofía política contemporánea se suele hablar de dos modelos contrapuestos de construcción de las identidades: el modelo ilustrado, cuyo más alto representante sería el cosmopolitismo de cuño kantiano, por un lado, y por otro, el romanticismo político que está en la base de todos o casi todos los procesos de construcción de identidades nacionales desde el siglo XIX. A mi juicio, la forma barroca de identidad se plantea como un tercer "tipo ideal" (en terminología weberiana), claramente diferenciado de los otros dos y no asimilable a ellos. Así pues, nos encontramos con tres tipos ideales de construcción de identidades políticas: barroco, romanticismo y cosmopolitismo ilustrado. Y además, la identidad barroca no es sólo un elemento del pasado, sino que se encuentra presente en la actualidad, en todas las circunstancias en que alguien no puede mostrarse plenamente como es, sino que ha de disimular su verdadera forma de pensar o su condición y opiniones políticas o de otro tipo.

Parto de la hipótesis de que la identidad -personal o colectiva- es siempre una narración compleja. Y esta identidad narrativa se construye en relatos, mitos de pertenencia 0 de origen, se vertebra en torno a metáforas centrales del yo y de la sociedad, al tiempo que se expresa en imágenes artísticas. Como ya he dicho, en la filosofía política contemporánea sobre el tema de la identidad colectiva se suele contraponer el cosmopolitismo ilustrado frente a los particularismos románticos. Sin embargo, pienso que la contraposición más interesante se da entre el Barroco y el Romanticismo y se formula también en torno a metáforas contrapuestas.

La metáfora central de la identidad barroca es el teatro, la creación del propio personaje, la apariencia, los principios de la simulación y la disimulación. En torno a la categoría de Theatrum mundi se engarzan toda otra serie de ideas que componen un campo metafórico muy rico. La identidad barroca se define por la complejidad del yo, de un sujeto doble que ha de fingir ser un personaje distinto a quien realmente es en su fuero interno. Por otra parte, la metáfora central de la identidad romántica es la autenticidad. En torno a ella se compone un campo metafórico en el que encontramos otras metáforas como las "fuentes del yo" (Charles Taylor), el "bosque originario" (Jon Juaristi) o 
la transparencia del individuo. La identidad romántica busca esa transparencia del yo frente a la postulación barroca del disimulo, se constituye como elemento constructor de nuevas nacionalidades y apuesta por identidades individuales fuertemente identificadas con lo nacional. Frente a la complejidad del yo barroco nos encontramos aquí con un proceso de reducción del yo a una de sus facetas, la identidad nacional, que engloba la pertenencia familiar $y$ exige del individuo lealtad y autenticidad.

Cabe afirmar que la pregunta por el yo, por lo que hoy denominariamos la identidad personal, parece ser una constante del Barroco, tanto en los planteamientos filosóficos como literarios. Descartes fundamenta su filosofía en la duda metódica hasta que encuentra un elemento del que ya no puede dudar: la propia existencia, la identidad, el yo. De un modo paralelo, en la literatura, Calderón nos presenta a Segismundo elucubrando sobre su identidad, sobre la realidad o ensoñación de la vida humana, o también a ese otro personaje en Eco y Narciso que se encuentra en medio de un bosque -en medio de la confusión y oscuridad del mundo, según comenta el maestro José Antonio Maravall $(1975,343-344)^{2}$ - y que ignora todo acerca de su yo y de la vida en sociedad. Por su parte, Gracián da comienzo a su obra cumbre -El Criticón- con la pregunta por el yo en la primera conversación tras el encuentro de sus dos personajes Critilo (el hombre de juicio) y Andrenio (el hombre natural). La divisa clásica del Conócete a ti mismo alcanza una nueva expresión en el Barroco, pues "quien comienza ignorándose, mal podrá conocer las demás cosas" del universo y además, "de nada sirve conocerlo todo si a sí mismo no se conoce"3.

La pregunta barroca por el yo se plantea en un mundo profundamente conflictivo y dividido, compuesto de contrarios en guerra permanente entre sí. Cabría decir que la identidad barroca se constituye en la lucha por el conocimiento - conocimiento de la naturaleza, de los demás y de uno mismo- y no tanto como una lucha por el reconocimiento de los derechos, tal y como se entiende hoy el problema de la identidad colectiva en la filosofía política. Para Gracián, por ejemplo, la lucha está presente a los tres niveles señalados: en la naturaleza ya que "todo este universo se compone de contrarios y se concierta de desconciertos", en la vida social concebida como una lucha generalizada de todos contra todos, e incluso en el interior del ser humano, escenario de la discordia más encendida.
En uno de los capítulos de este libro en construcción distinguiré ocho metáforas o figuras principales de la identidad barroca en las que el yo se expresa hacia el exterior o también se entiende a sí mismo. Cada una de las figuras de la identidad es una manera de comprender el mundo desde la perspectiva del individuo y tiene una fuerte impronta en las artes visuales, pues no en vano la época privilegia de una manera especial el sentido de la vista: la cultura del Barroco es una cultura eminentemente visual en la que las imágenes transmiten contenidos pedagógicos importantes en una incipiente "sociedad de masas" que ha de ser dirigida desde un poder concebido como absoluto ${ }^{4}$. Mis ocho figuras de la identidad barroca serán: el teatro, el espejo, la calavera, el camino, el libro, el baluarte, el laberinto y el sueño. Pero en este artículo sólo me voy a referir a las dos últimas.

\section{EL YO EN SU LABERINTO}

Sorprende a primera vista la profusión de laberintos en la época renacentista y barroca: juegos en los jardines de los palacios, laberintos espirituales, el alma concebida como arrojada al laberinto de la vida del que sólo la puede sacar un Cristo-Teseo, poemas laberínticos, laberintos como emblemas y empresas personales, sellos de arquitectos y divisas nobiliarias, laberintos del amor, o sucesos históricos como la guerra de los treinta años expresados como un laberinto de acontecimientos en los que resulta imposible orientarse. La figura del laberinto define todos los niveles de la experiencia social: el mundo en su conjunto, la sociedad cortesana como maraña de intenciones ocultas que impiden la transparencia, el palacio confuso de que nos habla un título de Lope de Vega, laberintos en los suelos de iglesias y catedrales, el infierno como laberinto, la muerte en el centro del laberinto de la vida, los bastiones defensivos de las fortalezas adquieren forma de laberintos, la ciudad como dédalo inextricable de calles en que uno se pierde o el individuo como embrollo de intenciones y movimiento de pasiones ocultas o en conflicto que el yo no comprende 0 no puede dominar ${ }^{5}$.

Escrito en 1623 y publicado en 1631, el famoso libro del sabio checo John Amos Comenius (Komensky, 15921670) El Laberinto del Mundo y el Paraíso del Corazón relata el viaje alegórico de un joven a través del mundo

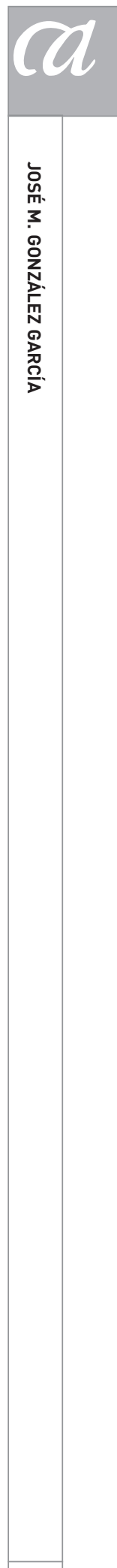

469 
en compañía de un representante de la diosa Sabiduría y otro representante del Engaño. El mundo es definido como un laberinto mucho más confuso que el de Creta, en donde nadie debe entrar solo, pues jamás encontrará la salida, especialmente en esta época de desconcierto y falsedad ${ }^{6}$.

También el viaje de la vida se transforma en un laberinto en la edición de la Iconología de Ripa publicada por Johann Georg Hertel en Augsburgo, ya en pleno siglo XVIII, y cuya lámina 6 podemos ver más abajo. El grabado fue realizado por Jeremias Wachsmuth según un dibujo original de Gottfried Eichler el joven. En la figura, el camino de la vida de la Tabla de Cebes parece haber dado lugar a una construcción laberíntica con tres círculos concéntricos que conducen al ser humano desde el nacimiento a la muerte. Hermann Kern describe asi esta imagen:

\section{El laberinto como símbolo del curso de la vida humana: en la entrada del laberinto se muestra a un niño de pie y con dos ramos de flores; un joven con una hoz y espigas de trigo en las manos aparece en el círculo exterior; una mujer madura con uvas es representada en el siguiente circuito; un viejo sentado frente al fuego en el circuito más interno. Es una ilustración de las cuatro edades de la humanidad $y$, al mismo tiempo, una imagen de las cuatro estaciones del año. En el centro, sobre una plataforma se muestra a la muerte con la guadaña y el reloj de arena: destino final de la existencia humana (Kern, 2000, 223)'.}

Con razón ha señalado Fernando R. de la Flor que la transición del Renacimiento al Barroco puede entenderse simbólicamente como la sustitución del bivio (o encrucijada de caminos ante la que el individuo debe reflexionar cuál de ellos seguir en la vida) por el laberinto o confusión de senderos donde resulta difícil encontrar una salida. La figura renacentista de "Hércules en la encrucijada" abre paso al "Minotauro en su laberinto", la plaza abierta del ancho mundo se clausura en una construcción cerrada de la que no hay salida posible más que gracias a un hilo de Ariadna que no siempre se encuentra ${ }^{8}$. El gusto renacentista por los caminos de la vida se transforma en una figura de desorden, desconcierto, confusión y caos, en un encierro entre las paredes del laberinto a la búsqueda incierta de una escapatoria. De Cervantes a Gracián, los caminos abiertos de La Mancha por los que transitan D. Quijote y Sancho a la búsqueda de aventuras se transforman en la profusión

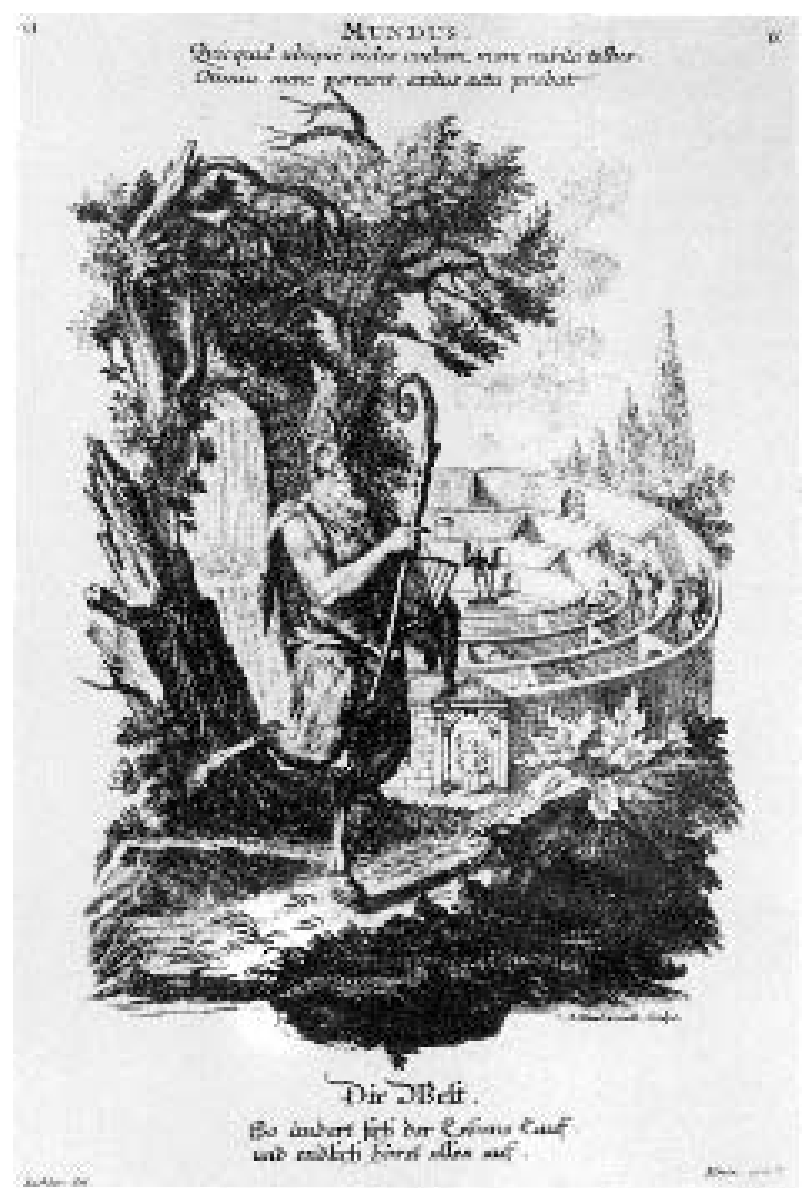

Figura 1. Iconología de Ripa, versión de Hertel, Augsburgo, 1758-60. Lámina 6

alegórica de laberintos de los que Andrenio y Critilo han de buscar la salida en El Criticón.

Después de haber sido aleccionados por el centauro Quirón, quien les muestra la depravación del "estado del siglo", en el que ya no hay héroes ni hombres eminentes en armas o en letras, todo anda al revés, trabucado, el mundo se ha convertido en Babel confusa y llena de mentiras, caos de la razón de Estado, en el "peregrino viaje de su vida" comprenden Andrenio y Critilo que han de entender todas las cosas al contrario de lo que muestran. Apariencia y realidad se oponen y la política se define como un gran artificio, como la forma de medrar y valer en el mundo, como el arte de ganar voluntades y tener amigos y sobre todo como "el hacer parecer las cosas, que es el arte de 
las artes". En la crisis VII de la primera parte titulada "La Fuente de los Engaños", -pues quien bebe de ella todo se lo traga y todo lo trueca- describe Gracián la ciudad como un "modelo de laberintos y centro de minotauros":

Divisábase ya la gran ciudad por los humos, vulgar señal de habitación humana, en que todo se resuelve. Tenía extremada apariencia, y mejor cuanto más de lejos. Era increible el concurso que de todas las provincias y a todos los tiempos acudian a aquel paradero de todos, levantando espesas nubes de polvo que quitaban la vista. Cuando llegaron a ella, hallaron que lo que parecía clara por fuera, era confusa dentro; ninguna calle había derecha ni despejada: modelo de laberintos y centro de minotauros (Gracián, 1998, 168).

Andrenio y Critilo entran en la ciudad y a través de las calles de la Hipocresía, de la Ostentación y del Artificio llegan a la Plaza Mayor, que es el Palacio. Después de haber descrito la ciudad como un laberinto, Gracián describe ahora el palacio como una confusión de espacios, espacioso y nada proporcionado, ni trazado a escuadra, lleno de ángulos y traveses, sin perspectiva ni igualdad, con muchas puertas falsas, más torres que en Babilonia y ventanas verdes ("color alegre por lo que promete y el que más engaña"). Dentro vivía, o mejor yacía, "aquel tan grande como escondido monarca, que muy entretenido asistía estos días a unas fiestas dedicadas a engañar al pueblo no dejándole lugar para discurrir en cosas mayores" (Gracián,1998, 172). Así pues, la ciudad y el palacio como laberintos confusos en los que es preciso encontrar un hilo para orientarse. Esta idea es corroborada varias crisis más adelante al definir la corte también como un laberinto. En efecto, cuando Andrenio y Critilo divisan de lejos la corte, definen a Madrid de una manera contrapuesta, como corresponde a los personajes que representan, el hombre natural y el hombre de criterio. Preguntados por el Sabio -la figura alegórica que les acompaña en el camino- por lo que están viendo, responde cada uno lo siguiente:

- Veo dijo él [Andrenio] una real madre de tantas naciones, una corona de dos mundos, un centro de tantos reinos, un joyel de entrambas Indias, un nido del mismo fénix y una esfera del Sol Católico, coronado de prendas en rayos y de blasones en luces.

- Pues yo veo -dijo Critilo- una Babilonia de confusiones, una Lutecia de inmundicias, una Roma de mutaciones, un Palermo de volcanes, una Constantinopla de nieblas, un Londres de pestilencias y un Argel de cautiverios (Gracián, 1998, 242).

El Sabio se despide y Critilo y Andrenio entran en Madrid por la espaciosa calle de Toledo, topando en primer lugar con una librería. En ella entra Critilo y le pide al librero que les venda un "ovillo de oro". Ante la extrañeza del librero que no entiende la demanda, tercia en la conversación un cortesano para aclarar que lo que le están pidiendo es "una aguja de marear en este golfo de Circes". Tampoco ahora comprende el librero la nueva metáfora y contesta que no vende oro ni plata sino libros, que son mucho más preciosos. Critilo aclara que eso es lo que buscan, libros "y entre ellos alguno que nos dé avisos para no perdernos en este laberinto cortesano". La corte también, pues, como laberinto en el que es preciso orientarse con la ayuda de los libros, ovillos de oro de Ariadna o brújulas en un mar peligroso por sus tormentas frecuentes.

Gracián da su propia versión de la crítica -ya tradicional en su momento histórico- de la corte como un confuso laberinto. Un ejemplo de esta tradición sería el libro de Julio Antonio de Brancalasso, publicado en Nápoles por los impresores Juan Bautista Gargano y Lucrecio Nucci en el año de nuestra salvación 1609, con el complejo y descriptivo título de LABIRINTO DE CORTE. Con IOS DIEZ PREDICAMENTOS DE CORTESANOS. Dos libros en los quales están comprehendidos todos los bienes y males que pueden, y suelen en las Cortes de Príncipes a los que las siguen. Y SE DAN DIFERENTES MODOS de salir felizmente del Labirinto para gloria de Dios, y con honras, y riquezas del mundo, como también para fundar una Corte Real. CON LOS AVISOS necesarios para ganar y conservar la gracia de los mismos Príncipes, y de todos los géneros de personas que en cualquier manera tratan con ellos. Resumidos de los autores poli'ticos Catholicos que hasta agora han escrito en materia de estado, y de buen govierno. POR EL DOCTOR JULIO ANTONIO BRANCALASSO Sacerdote natural de la ciudad de Turfi. El libro describe los trabajos y penas del Privado y de los cortesanos en el "labirinto" de la corte, en medio del cual se halla el cruel Minotauro, bravo y fiero animal de quien nadie puede escaparse:

En el medio de tantas y tan grandes desventuras está el Minotauro, el remordimiento de la propia conciencia; el continuo cuydado de los malos sucesos que han tenido otros

ARBOR CLXXXVI 743 mayo-junio[2010] 467-478 ISSN: 0210-1963 
Privados; el disgusto y la congoja de la mala satisfacción que se ha dado à tantos, y tan graves pretendientes que pueden en algún tiempo, y manera vengarse (Brancalasso, 1609, 16).

Un segundo ejemplo es el Emblema 31 (Tanta est fallacia tecti) de la primera centuria de los Emblemas Morales de Sebastián de Covarrubias Orozco, libro publicado en Madrid en 1610. En el cuerpo de dicho Emblema se muestra a un individuo que envejece y muere en el laberinto de la corte, a pesar de estar siempre deseando salir de ella.
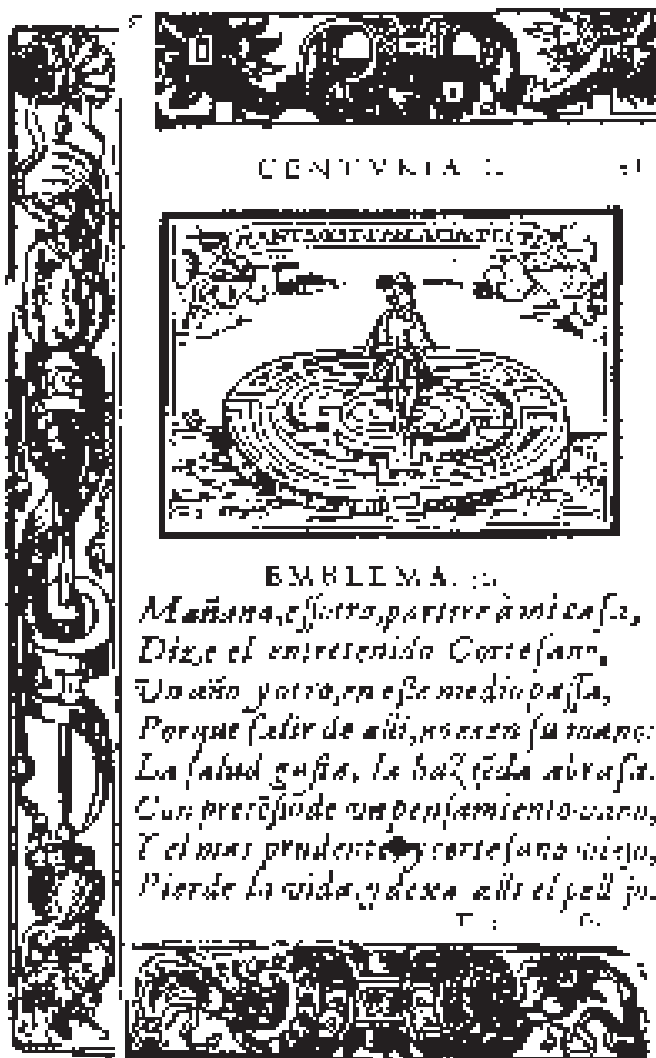

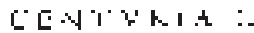
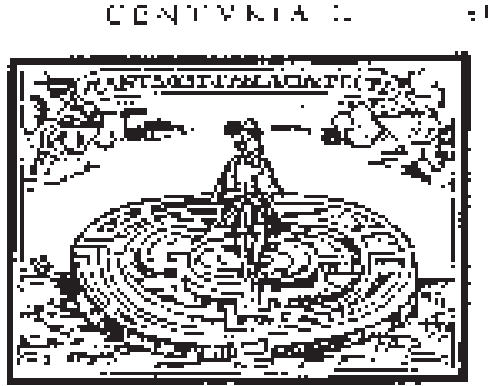

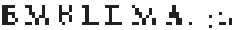

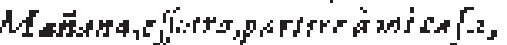

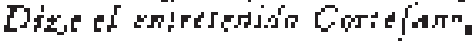

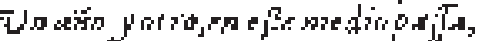

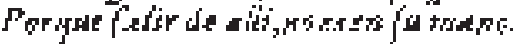

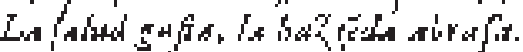

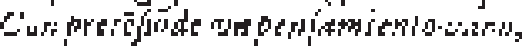

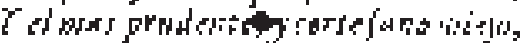

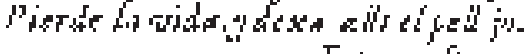

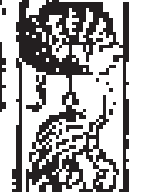
13 rits. 40 (4) $x=$ $x_{1}$ $\rightarrow 3$ (Pats $+5$ (aist

Figura 2. Sebastián de Covarrubias Orozco, Emblema 31 de sus Emblemas Morales, 1610.

Así pues, el mundo en su conjunto, la sociedad cortesana y la ciudad son vistos como laberintos confusos en los que se desarrolla la vida humana. Pero también el individuo es concebido como laberinto, según podemos ver en los dos ejemplos con los que concluyo este apartado. En primer lugar, el caballero del laberinto en el pecho, óleo de Bartolomeo Veneto realizado probablemente en Milán en torno a 1510. Esta pintura ha sido objeto de múltiples interpretaciones en las que no puedo detenerme aqui ${ }^{9}$. Sólo quiero destacar el broche del sombrero en el que a modo de empresa política o familiar aparece un barco hundiéndose en el mar con un hombre a bordo y sobre la escena, la divisa "La esperanza me guía". Pero lo más interesante son los veintidós nudos de las vestiduras $y$, sobre todo, el laberinto en el centro del pecho, detrás de las dos manos que sostienen una espada en actitud de defensa de la propia interioridad. Kern recuerda que el laberinto se bordaba tradicionalmente en las vestiduras oficiales de los emperadores bizantinos como símbolo del secreto que debe guardar el hombre de estado: el laberinto del silencio. El secreto se convertirá en una de las armas fundamentales de la política barroca, junto con la simulación y el disimulo. Pero aquí podemos ver también el laberinto como un signo de la complejidad del yo, que se oculta en un dédalo de corredores y estancias complejas y tiene que luchar con su propio Minotauro interior. La figura de la transparencia del yo representada por Momo y su ventana en el pecho que dejaba ver todas las intenciones del corazón deviene imposible en la sociedad cortesana del Renacimiento y sobre todo del Barroco, de forma que el cristal es sustituido por un confuso laberinto que oculta el pecho del individuo, al tiempo que señala la complejidad de su interior. 0 también la ventana en el pecho deviene innecesaria para la mirada escrutadora de Gracián, quien ayuda a desvelar la verdad -o la mentira- oculta en el corazón de los otros ${ }^{10}$.

Por último, Roger Bartra ha analizado magistralmente el uso de la metáfora del laberinto interior en las teorias humorales de los médicos del Siglo de Oro español, quienes describen la fuerza de la melancolía en las funciones mentales del individuo y en las actitudes sociales de la época. Los médicos acaban refiriéndose al complejo universo cerebral, a la "casa del alma", como un laberinto cercano a las inquietudes cotidianas, pero también conectado con los secretos de la astrología y los misterios de la teología:

No era fácil orientarse en ese laberinto mental y cerebral de temperamentos, fluidos, emanaciones, espíritus, luces e impresiones. La idea de un laberinto interior era importante, pues dejaba un lugar para las opciones: a pesar de la influencia de astros, humores y temperamentos, la máquina cerebral debía ser flexible, ya que el libre albedrío estaba encerrado en 


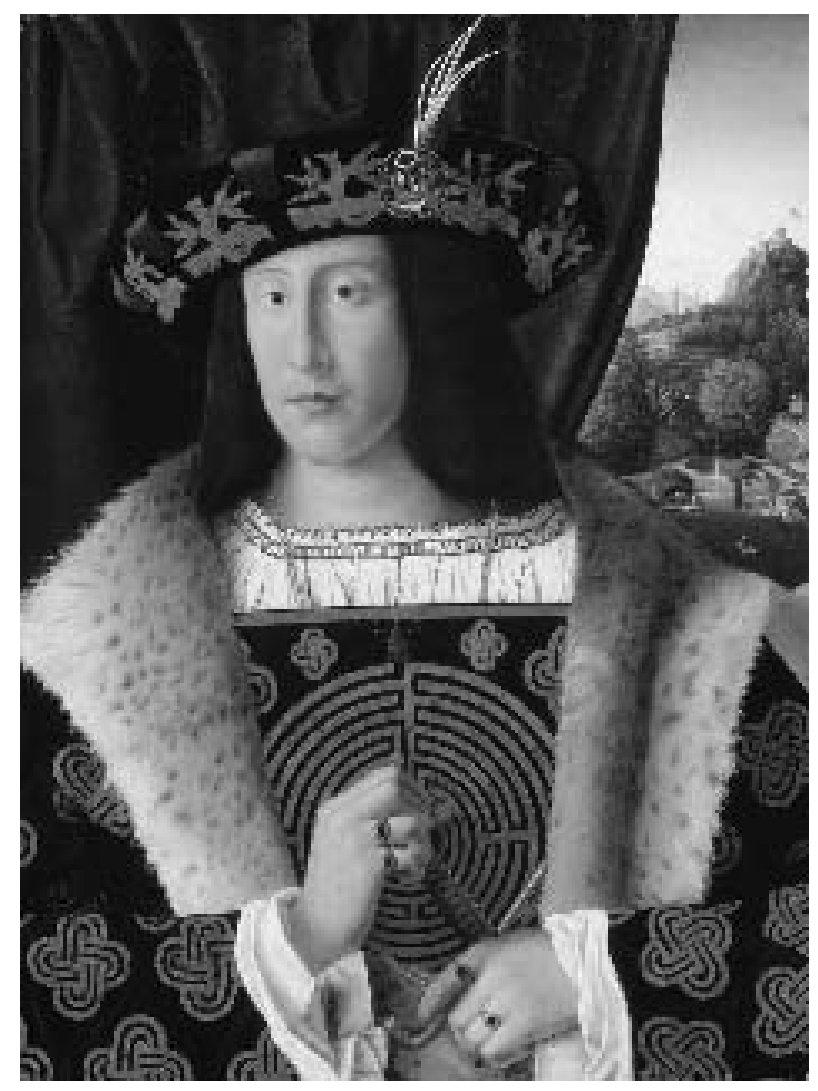

Figura 3. Bartolomeo Veneto, Retrato de un hombre, c. 1510. Fitzwilliam Museum, Cambridge.

la caja craneana y sus movimientos ocasionaban un cierto desorden en la casa del alma (Bartra, 2001, 210-211).

Los laberintos del corazón y del cerebro son el último nivel de una metáfora que intenta explicar la complejidad y la confusión del mundo, de un espacio y un tiempo convulsos, de la sociedad cortesana, de la ciudad, del propio interior del ser humano y su identidad personal.

\section{EL SUEÑO DE LA IDENTIDAD O LA IDENTIDAD COMO SUEÑO}

Se trata de un tópico que, viniendo de épocas anteriores, recorre todo el siglo XVII, desde Calderón a Sor Juana, y que tiene también su expresión en la pintura y en las canciones anónimas o populares, como aquélla que dice:

\author{
Hombre, que la vida \\ pasas durmiendo, \\ si conoces que duermes, \\ vive despierto, \\ si presumes que vives, \\ muere durmiendo.
}

Este paralelismo entre sueño y muerte es también central en Sor Juana Inés de la Cruz, quien escribe que el cuerpo, poseído por el sueño, en medio de un absoluto silencio, era "un cadáver con alma, /muerto a la vida y a la muerte vivo". Por otro lado, La Bruyère insistirá en la vida como sueño confuso del que uno sólo despierta cuando comienza a morir" ${ }^{11}$.

El sueño como figura de la identidad resulta especialmente importante en el Barroco y está relacionada también con la concepción de la vida como un gran teatro, en que cada uno de los actores sueña el papel que representa hasta despertar, que es el morir a esta vida y el comenzar a vivir en la otra: "el hombre que vive sueña / lo que es hasta despertar" afirma Segismundo. "La vida es un sueño y el mundo, un teatro" representa una fórmula muy extendida en la época y que, de una manera o de otra, encontramos en muchos escritores. Tal vez quien mejor la formula es Calderón en los títulos de sus obras más famosas, La vida es sueño y El gran teatro del mundo.

La metáfora del sueño significa la brevedad de la vida pues, según formulará de nuevo Calderón, "que toda la dicha humana / en fin pasa como sueño". El mundo es definido por Clotaldo como un confuso laberinto en el que la razón no puede encontrar el hilo para salir. $Y$ en la confusión entre realidad y ensoñación, debe Segismundo obrar bien, aunque sea en sueños.

Además de la versión calderoniana "a lo divino", nos encontramos en la época con otras versiones "humanas, demasiado humanas", como la narrada por Quevedo, quien representa al sueño como cumplimiento de una fantasía o deseo erótico, varios siglos antes de que Freud escribiera su famosa obra sobre La interpretación de los sueños. Dice así el soneto de Quevedo:

\section{¡Ay Floralba! Soñé que te.... ¿dirélo? Sí, pues que sueño fue: que te gozaba. ¿Y quién, sino un amante que soñaba, juntara tanto infierno a tanto cielo?}


Mis llamas con tu nieve y con tu yelo, cual suele opuestas flechas de su aljaba, mezclaba Amor, y honesto las mezclaba, como mi adoración en su desvelo.

Y dije: "Quiera amor, quiera mi suerte, que nunca duerma yo si estoy despierto, y que si duermo, que jamás despierte".

Mas desperté del dulce desconcierto; y vi que estuve vivo con la muerte, y vi que con la vida estaba muerto ${ }^{12}$.

Por otro lado, Quevedo expresa el desengaño barroco ante la vida que se deshace en nada, que está destinada a no durar, ya que, según afirma en otro soneto "¡Fue sueño ayer, mañana será tierra! ¡Poco antes, nada; y poco después, humo!" La vida se consume en un momento y la identidad humana es un sueño entre la nada y la muerte. Pero lo más interesante de Quevedo es su utilización de la ficción del sueño como mecanismo de crítica de la sociedad de su tiempo. En efecto, sus Sueños y Discursos, son un análisis profundo y una crítica de muchos personajes, individuos de toda laya y condición, mentirosos, hipócritas, actores en el Theatrum mundi de la vida. Se trata también de un proceso de aprendizaje para llegar a distinguir la realidad profunda de la vida frente a las apariencias externas, según afirma el viejo en El mundo por de dentro: "Eso todo es por fuera, pero agora lo verás por dentro y verás con cuánta verdad el ser desmiente a las apariencias" (Quevedo, 2003, 370). Pienso que tiene razón Juan F. Villar Dégano en su comparación entre la ficción del sueño en la escritura de Quevedo y en la pintura de Antonio de Pereda, al afirmar que "Ouevedo hace lo contrario que Calderón, sueña el infierno -que es la realidad de la vida- para destacar más esta realidad deformándola, y en ella al hombre con sus imperfecciones" (Villar Dégano, 1981, 53).

Quisiera referirme al cuadro de Antonio de Pereda, El sueño del caballero o Desengaño de la vida, pintado hacia 1650 y que se puede admirar en una de las salas centrales del Museo de la Academia de Bellas Artes de San Fernando

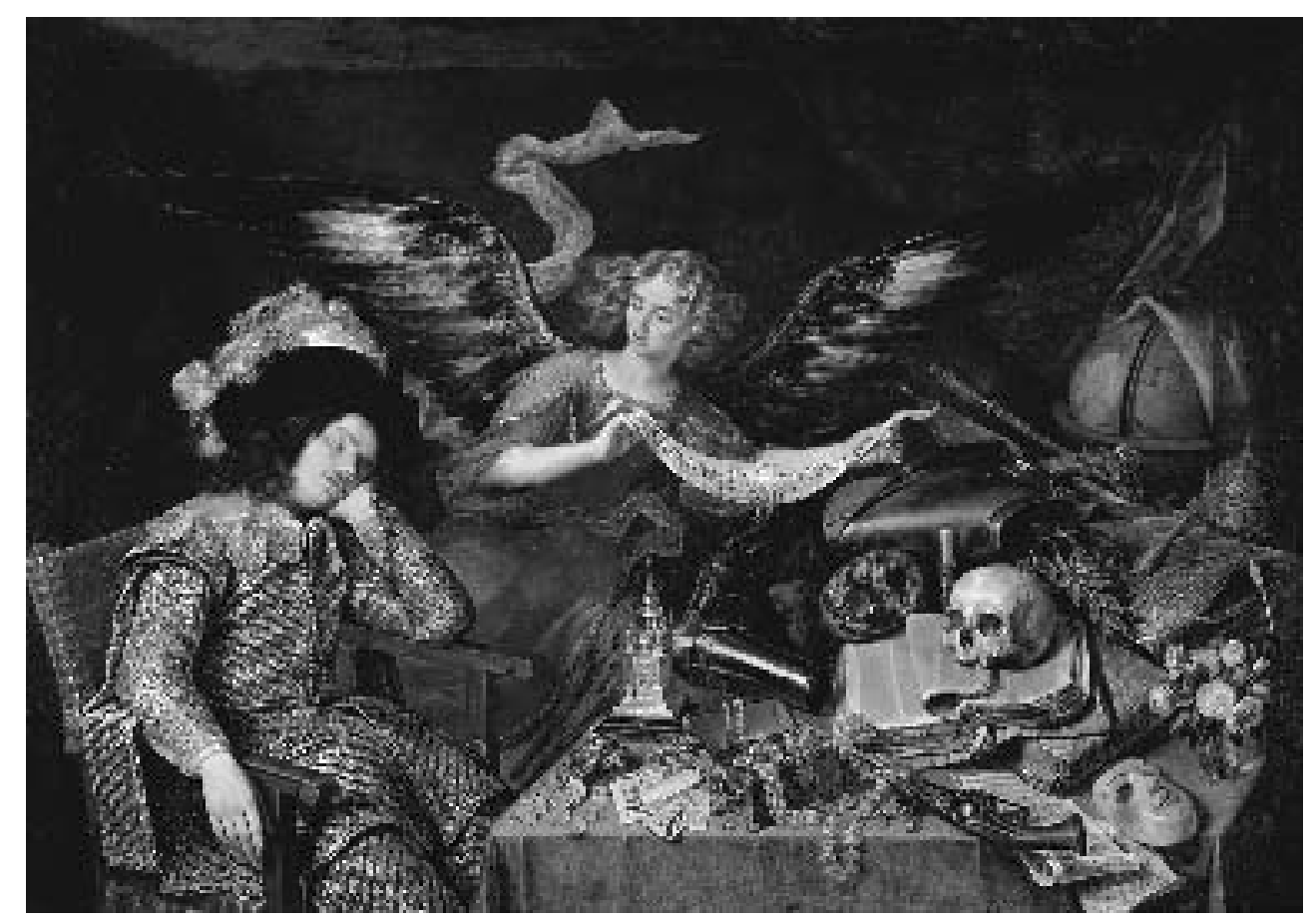

Figura 4. Antonio de Pereda, El sueño del caballero o Desengaño de la vida, Madrid, Museo de la Real Academia de Bellas Artes de San Fernando. 
en Madrid. Pereda nos muestra una escena en la que un joven caballero, elegantemente vestido, se ha quedado dormido sentado en un sillón y con la cabeza apoyada en el puño izquierdo, en una postura de reflexión melancólica que hiciera famosa Durero en su grabado de la Melancolía. Pereda desdobla la figura del ángel de la melancolía dureriana: transforma el puño sobre el rostro del ángel de Durero en la misma actitud de un caballero sumido en un profundo sueño, y el ángel alado de la melancolía se aparece en el sueño mirando al joven, presentándole toda una panoplia de objetos sobre la mesa y sosteniendo en las manos una cartela con la inscripción: Aeterne pungit cito volat et occidit (Eternamente hiere, vuela veloz y mata). Además, la inscripción se refuerza con la imagen de la flecha en el arco. El sueño de la melancolía barroca conduce a la desilusión y desengaño de la vida, a la desvalorización de todos los honores y riquezas del mundo que se le presentan al caballero como los objetivos de su existencia. Resuenan las palabras del Eclesiastés: "Vanidad de vanidades y todo vanidad". Pereda llega aquí a su máxima altura como pintor de Vanitas, tema central de su obra y sobre el que vuelve una y otra vez en su Alegoría de la Vanidad o también en su Vanitas del Kunsthistorisches Museum de Viena. En los tres casos, aparece la figura central del ángel alado de la melancolía, advirtiéndonos de la caducidad de todos los asuntos humanos. Me parece que es posible considerar este cuadro de Pereda como un elemento central de mi interpretación, pues en él se representan todas las metáforas de la identidad barroca que analizaré en mi libro ${ }^{13}$ :

1. La identidad como teatro está simbolizada por el rico traje del caballero, vestido para representar su papel en el Theatrum mundi de la vida social. Y además, sobre el extremo derecho de la mesa se encuentra la máscara que define también el carácter de teatralidad de la vida humana.

2. El espejo barroco está en el centro de la mesa, reflejando otra figura de la identidad barroca: la calavera.

3. La calavera como imagen de la identidad ("Y hoy calavera ya soy") juega un papel central en la composición y está pintada en dos posiciones diferentes, además del reflejo en el espejo. Hay también otros símbolos de la muerte y de la caducidad de la vida: las flores ("flor de un día, el mismo sol que las ve nacer las ve morir"), la vela apagada, el reloj, o la flecha que vuela y mata en la cartela del ángel.

4. El camino de la vida está presente de manera indirecta pues todo el cuadro se podría interpretar en referencia a la composición alegórica de Rafael, El sueño del caballero, pintada en 1501. Aquí, León el Africano (en una nueva versión de la figura de Hércules en la encrucijada) tiene que elegir entre las dos figuras que se le aparecen mientras duerme en una encrucijada del camino de la vida: Atenea le señala el difícil camino de la virtud, mientras que Venus le muestra el fácil camino del placer. De manera similar, el caballero de Pereda ha de rechazar los placeres y honores de este mundo que son mera y fugaz vanidad. Villar Dégano ve en el cuadro una síntesis perfecta de los tópicos barrocos de la existencia como camino y del individuo como homo viator, "itinerante de las cosas hacia una trascendentalidad que sólo puede ser Dios (o la nada en una mayor heterodoxia)" (Villar Dégano, 1981, 59).

5. El laberinto podría verse en la multiplicidad y confusión de objetos que pueblan los sueños del dormido caballero.

6. La identidad como libro aparece pintada en los mamotretos - uno abierto y otro cerrado- bajo la calavera: los libros de la vida (y de la muerte).

7. La fortaleza barroca del yo se muestra en la armadura y las armas de una identidad siempre a la defensiva, encerrada en la torre barroca del reloj, que de nuevo nos recuerda que somos tiempo, una breve cláusula de tiempo entre la cuna y la sepultura.

8. $Y$, por último, la identidad como sueño o el sueño de la identidad barroca es el tema central de toda la composición.

De esta manera, podemos visualizar todas las metáforas de la identidad barroca en el óleo de Antonio de Pereda, El sueño del caballero o Desengaño de la vida. Se trata, tal vez junto con las "vanidades" de Valdés Leal, de uno de los mejores exponentes de la meditación de la pintura española del siglo XVII sobre los problemas existenciales de la vida humana y acerca de la propia identidad del individuo barroco.

ARBOR CLXXXVI 743 mayo-junio[2010] 467-478 ISSN: 0210-1963 


\section{CODA FINAL: HACIA UNA SUPERACIÓN DE LOS DOS ROSTROS DE LA MELANCOLÍA}

La doble perspectiva de Heráclito y Demócrito, del filósofo que llora y del filósofo que ríe, se convierte en los siglos XVI y XVII en un tópico de la literatura, de la filosofía y de las artes plásticas. A modo de ejemplo podemos ver el grabado de Crispyn de Passe con los dos filósofos en actitudes contrapuestas sobre el globo terráqueo puesto al

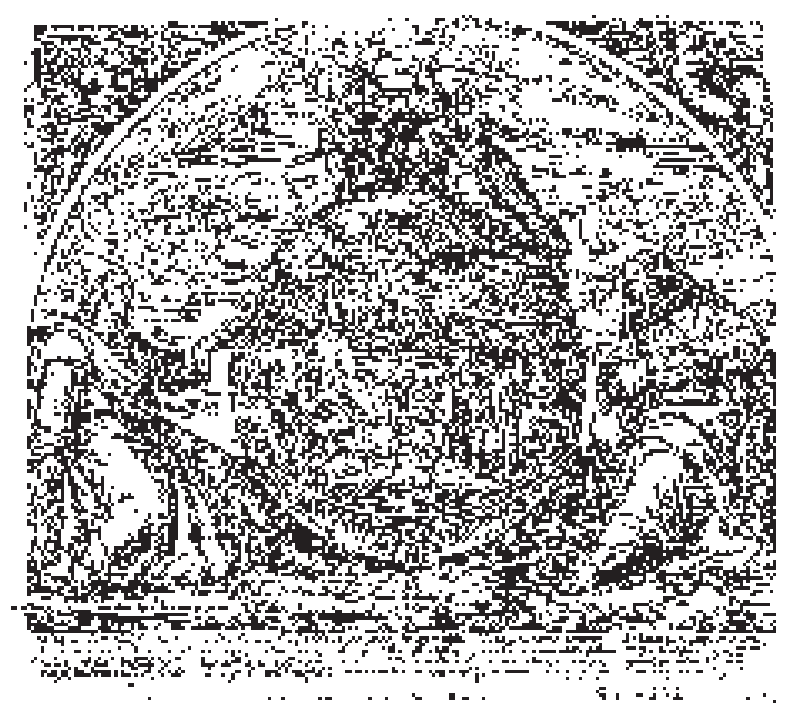

Figura 5. Crispyn de Passe, "El mundo al revés. Demócrito y Heráclito". revés, con la cruz invertida, hacia abajo, haciendo visible otro tópico de la época: "el mundo al revés".

Encima del globo terráqueo, el diablo triunfante pone la corona de la victoria sobre la cabeza de un hombre que seduce a una mujer ofreciéndole riquezas. En ese mundo invertido triunfa el mal sobre el bien, la violencia domina todas las relaciones humanas y la Naturaleza provoca los desastres desatando las tormentas. La vida humana no es más que vanidad de vanidades como figura arriba del todo y lo dejan claro también los dos putti, con la calavera, el reloj de arena y las pompas de jabón. Frente a este espectáculo teatral sólo caben las dos posturas de los filósofos: el llanto de Heráclito sobre la estupidez de los hombres o la risa de Demócrito como terapia sobre la locura de sus semejantes.

Tiene razón Remo Bodei al establecer, en su magnífico estudio acerca de la geometría de las pasiones, que la risa y el llanto sobre los acontecimientos humanos y sobre la manera en que los hombres representan su papel en el teatro del mundo equivalen a los dos rostros de la melancolía (Bodei, 1995, 164-173). Y ese doble rostro únicamente puede ser derrotado con la fórmula de un gran filósofo del Barroco, Baruch Spinoza: "He tenido sumo cuidado de no burlarme de los actos humanos, ni lamentarme o maldecirlos, sino comprenderlos" (Spinoza, 1966, 143).
NOTAS

Recibido: 1 de diciembre de 2008

Aceptado: 1 de junio de 2009
1 Quisiera agradecer de manera explícita a Peter Burke y a Maria Lúcia Garcia Pallares-Burke su amistad, el constante intercambio intelectual mantenido a lo largo de los últimos diez años y haber hecho mucho más humanas y productivas mis sucesivas estancias en la Universidad de Cambridge.

2 Mi deuda con los planteamientos de Maravall es constante a lo largo de este trabajo. También han sido fun- damentales los libros de Fernando R. de la Flor sobre el Barroco, especialmente los señalados en la bibliografía como 2002, 2005 y 2007.

3 Véase la crisis nona de la primera parte de El Criticón, titulada "Moral anotomía del Hombre".

4 Cfr. Maravall, 1975, 129-304.

5 Un magnífico recorrido por la historia cultural del laberinto puede encontrarse en el libro de Kern, Hermann (2000). Interesante resulta también el libro de Hocke, Gustav René (1963).

6 Cfr. Comenius, John Amos (1942). 
7 El propio Kern señala la relación de este grabado con la alegoría del camino de la vida en la Tabla de Cebes.

8 Cfr. R. de la Flor, Fernando (2005, 65). La figura del laberinto es clave en la argumentación de este libro, especialmente en el capítulo 3 ("Laberintos del yo"), pero también en los capítulos 1 ("Humanismo ingenuo") y 2 ("El príncipe escéptico"). En todos ellos insiste el autor en el papel central del laberinto como un gran emblema de la época barroca.

9 Cfr. Kern, Hermann, 2000, 203.

10 Véase el capítulo III "La historia de Momo y la ventana en el pecho" en el libro de Egido, Aurora, 2000, 49-91.

11 Jean de La Bruyère $(1998,221)$ afirma lo siguiente: "La vida es un sueño. Los viejos son los que le han tenido más largo y no comienzan a despertar sino cuando es preciso morir. Si echan entonces una ojeada sobre todo el curso de sus años, muchas veces no encuentran ni virtudes ni acciones loables que distingan los unos de los otros: confunden sus diferentes edades y no encuentran en ellas nada que puedan hacerles medir el tiempo que han vivido. Han tenido un sueño confuso, informe y sin ilación; sin embargo, como los que despiertan, sienten haber dormido largo tiempo".

12 Quevedo, Francisco de (1963, 363364), Poemas amorosos, número 336. Véase la interpretación de este poema en Ayala, Francisco, 1963, 7-19.

13 También aparece en el cuadro otra metáfora a la que no me he referido: la identidad como juego, simbolizada por la baraja de cartas encima de la mesa. Sobre la metáfora del juego puede verse el libro de J.-P. Etiènvre, 1990.

\section{BIBLIOGRAFÍA}

Ayala, Francisco (1963): Realidad y ensueño, Madrid, Gredos.

Bartra, Roger (2001): Cultura y melancolía. Las enfermedades del alma en la España del Siglo de Oro, Barcelona, Anagrama.

Bodei, Remo (1995): Una geometría de las pasiones. Miedo, esperanza y felicidad: filosofía y uso político, Barcelona, Muchnik.

Brancalasso, Julio Antonio de (1609): Labirinto de Corte. Con los Diez Predicamentos de Cortesanos, Nápoles, Juan Bautista Gargano y Lucrecio Nucci.

Burke, Peter (1995): La fabricación de Luis XIV, Madrid, Nerea.

Burke, Peter (1996): Hablary callar. Funciones sociales del lenguaje a través de la historia, Barcelona, Gedisa.

Burke, Peter (2001): Visto y no visto. El uso de la imagen como documento histórico; Barcelona, Crítica.

Burke, Peter (2002): Historia Social del conocimiento. De Gutenberg a Diderot, Barcelona, Paidós.

Burke, Peter (2006): Lenguas y comunidades en la Europa moderna, Madrid, Akal.

Burton, Robert (2001): The Anatomy of Melancholy, New York, New York Review Books.

Comenius, John Amos (1942): The Labyrinth of the World and the Paradise of the Heart, Chicago, III., The National Union of Czechoslowak Protestants in America.

Covarrubias Horozco, Sebastián (1610): Emblemas morales, Madrid, Luis Sánchez.

Egido, Aurora (2000): Las caras de la prudencia y Baltasar Gracián, Madrid, Castalia.

Etiènvre, Jean-Pierre (1990): Márgenes literarios del juego: una poética del naipe, siglos XVI-XVIII, London, Tamesis.
Gracián, Baltasar (1998): El Criticón (ed. de Cantarino, Elena), Madrid, Austral.

González Garcia, José M. (2006): La diosa Fortuna. Metamorfosis de una metáfora política; Madrid, Antonio Machado.

Hocke, Gustav René (1963): Die Welt als Labyrinth. Manier und Manie in der europäischen Kunst, Hamburg, Rowohlt.

Juaristi, Jon (2000): El bosque originario. Genealogías míticas de los pueblos de Europa, Madrid, Taurus.

Kern, Hermann (2000): Through the Labyrinth. Design and Meanings over 5,000 Years, Munich/London/New York, Prestel.

La Bruyère, Jean de (1998): Los caracteres, México, UNAM.

Maravall, José Antonio (1975): La cultura del Barroco. Análisis de una estructura histórica, Barcelona, Ariel.

Quevedo, Francisco de (1963): Obras Completas, vol. I, Poesía original (edición de Blecua, José Manuel), Barcelona, Planeta.

Quevedo, Francisco de (2003): Sueños y discursos de verdades soñadas, descubridoras de abusos, vicios y engaños en todos los oficios y estados del mundo, en sus Obras completas en prosa (edición de Arellano, Ignacio, volumen I, tomo I), Madrid, Castalia.

R. de la Flor, Fernando (2002): Barroco. Representación e ideología en el mundo hispánico, 1580-1680, Madrid, Cátedra.

R. de la Flor, Fernando (2005): Pasiones frías. Secreto y disimulación en el barroco hispano, Madrid, Marcial Pons.

R. de la Flor, Fernando (2007): Era melancólica. Figuras del imaginario barroco, Barcelona, Olañeta. 
Ripa, Cesare (1971): Iconologia. English, German \& Latin. Baroque and Rococo pictorial imagery: The 1758-60 Hertel edition of Ripa's Iconologia. Introd., tranlations, and 200 commentaries by Edward A. Maser, New York, Dover Publications.
Spinoza, Baruch (1966): Tratado político, introducción y traducción de Tierno Galván, Enrique, en edición conjunta con una selección del Tratado Teológico-Político, Madrid, Tecnos.

Taylor, Charles (1989): Sources of the Self. The Making of the Modern Identity,
Cambridge, Cambridge University Press.

Villar Dégano, Juan F. (1981): "La ficción del sueño en Quevedo y Antonio de Pereda", en Letras de Deusto, vol. 11, n. ${ }^{\circ} 21,39-62$. 